\title{
In vivo analgesic and anti-inflammatory effects of the essential oil from Tanacetum balsamita L.
}

\author{
Maryam Sharif $^{1}$, Parvaneh Najafizadeh ${ }^{1,2}$, Jinous Asgarpanah ${ }^{\circledR 3}$, Zahra Mousavi ${ }^{1 *}$
}

\begin{abstract}
${ }^{1}$ Department of Pharmacology and Toxicology, Faculty of Pharmacy and Pharmaceutical Sciences, Tehran Medical Sciences, Islamic Azad University, Tehran, Iran, ${ }^{2}$ Department of Pharmacology, Iran University of Medical Sciences, Tehran, IR Iran. ${ }^{3}$ Department of Pharmacognosy, Faculty of Pharmacy and Pharmaceutical Sciences, Tehran Medical Sciences, Islamic Azad University, Tehran, Iran.
\end{abstract}

\begin{abstract}
Tanacetum balsamita locally called Shahesparam is an aromatic plant that grows widely in Azerbaijan Province, Iran. Due to the widespread use of T. balsamita as a pain killer and relief of inflammatory based disorders in Iranian folk medicine and considering the high content of essential oil in T. balsamita aerial parts, we were prompted to investigate the anti-nociceptive and anti-inflammatory properties of T. balsamita essential oil (TBEO) for the first time. The carrageenan-induced Paw Edema was used for inflammation evaluation in rat, and hot-plate method was used for pain assessment in mice. Different doses of TBEO were administered. Morphine and Mefenamic acid were used as the standard drugs in antinociceptive and anti-inflammatory evaluation tests, respectively. TBEO $(100 \mathrm{mg} / \mathrm{kg})$ showed significantly anti-nociceptive activity in hot-plate test. The anti-inflammatory activity of TBEO was found to be more than mefenamic acid. The studied oil was analyzed by GC and GC-MS. The major component of the oil was characterized as carvone (39.8\%) which might be responsible for the observed activities. The results suggested that TBEO possessed biologically active constituents that had significant analgesic and anti-inflammatory effects which support the ethno-medicinal claims of the plant application in the management of pain and inflammation.
\end{abstract}

Keywords: Tanacetum balsamita. Essential oil. Analgesic. Antiinflammatory.

\section{INTRODUCTION}

Nowadays in spite of great progress in pharmaceutical sciences and synthesis of many drugs, pain control is still a problem. Opioid drugs have high analgesic properties but dependency precedes this pain reduction after a while. Non steroid anti-nociceptive and anti-inflammatory drugs, regardless of good efficacy, are also associated with different side effects including gastro intestinal problems. Hence, traditional medicine and herbal therapy have always been under consideration especially in countries with ancient history like Iran.

The genus Tanacetum (Compositae) consists of 26 species in Iran one of which is T. balsamita L. (Mozaffarian, 1996). T. balsamita locally called Shahesparam is an aromatic plant that grows widely in Azerbaijan Province, Iran. It has been used in Iranian folk medicine as a pain killer, tranquilizer and cardiac tonic

\footnotetext{
*Correspondence: Zahra Mousavi. Faculty of Pharmacy, Tehran Medical Sciences, Islamic Azad University, Yakhchal St., Shariati Ave., Tehran, Iran. Tel: +98 21 22640051, Fax:+98 21 22602059. E-mail: mosavi50@yahoo.com
}

(Nickavar, Amin, Mehregan, 2010). Previous studies reported that the Tanacetum sp. oil possessed digestive, diuretic, antitussive, analgesic/anti-inflammatory and antimicrobial effects (Lotfipour et al., 2008; Yousefzadi et al., 2009).

Also, T. parthenium extract has been reported to be an effective remedy for the prophylactic treatment of migraine, as it inhibits platelet aggregation, histamine release from mast cells (Johnson et al., 1985), and the production of prostaglandins, thromboxanes and leukotriens (Hayes, Foreman, 1987).

The Tanacetum sp. oil are used in Iranian traditional medicine for health problems such as inflammation, infection and urinary tract disorders (Lotfipour, Nazemiyeh et al. 2008; Yousefzadi, Ebrahimi et al. 2009). In addition to traditional medicinal usage, Shahesparam can also be used commercially in the food industry. In Iran, a tea prepared from $T$. sonboli is used to treat intestinal disorder, such as diarrhea. In addition, some of the medicinal Tanacetum species such as T. microphyllum and T. larvatum are useful for treating various inflammatory 
disorders (Abad, Bermejo, Villar, 2003) and protecting against indomethacin-induced ulcerogenesis, respectively (Petrovic et al., 2003).

Due to the widespread use of T. balsamita in Iranian and other traditional medicines for the relief of pain and inflammation and considering the high content of essential oil in T. balsamita aerial parts, we were prompted to evaluate the analgesic and anti-inflammatory activities of the essential oil and investigate the pharmacological basis for its folklore as an anti-inflammatory and pain killer agent. The present study explores the central analgesic and acute anti-inflammatory properties. The essential oil was analyzed by gas chromatography (GC) and gas chromatography-mass spectrometry (GC-MS) in order to identify the potentially responsible compounds for the observed properties. To the best of our knowledge, this is the first attempt to study the ethno-pharmacological properties of T. balsamita essential oil (TBEO) in a comprehensive manner.

\section{MATERIAL AND METHODS}

\section{Drugs, chemicals and plant material}

TBEO, anesthetic ether, morphine sulfate, mefenamic acid and carrageenan were purchased from Giah Essence Phytopharm Co., Iran, PubChem CID: 3283, Temad Pharmaceutical Co. (Iran), Temad Pharmaceutical Co. (Iran) and Sigma (U.S.A), respectively.

Powdered morphine was dissolved in saline. The solutions were prepared immediately before use and injected intraperitoneally in a volume of $10 \mathrm{~mL} / \mathrm{kg}$.

\section{Analysis of TBEO}

Analysis of TBEO was performed on a HP-6890 gas chromatography (GC) equipped with a FID and a DB-5 capillary column, $30 \mathrm{~m} \times 0.25 \mathrm{~mm}, 0.25 \mu \mathrm{m}$ film thickness, temperature programmed as follows: $60-240{ }^{\circ} \mathrm{C}$ at $4{ }^{\circ} \mathrm{C} / \mathrm{min}$. The carrier gas $\mathrm{N}_{2}$ was at a flow rate of $2.0 \mathrm{~mL} / \mathrm{min}$; the temperatures of injector port and detector were 250 and $300{ }^{\circ} \mathrm{C}$, respectively. Sample was injected by splitting and the split ratio was 1:10. The analysis of GC/MS was performed on a Hewlett-Packard 6890/5972 system with a DB-5 capillary column $(30 \mathrm{~m} \times 0.25 \mathrm{~mm}$; $0.25 \mu \mathrm{m}$ film thickness. The operating conditions were the same as described above but the carrier gas was He. Mass spectra were taken at $70 \mathrm{eV}$. The range of scan mass was from $40-400 \mathrm{~m} / \mathrm{z}$ at a sampling rate of $1.0 \mathrm{scan} / \mathrm{s}$. Quantitative data were obtained from the electronic integration of the FID peak areas. The components of TBEO were identified by their retention time, retention indices, relative to $\mathrm{C}_{9}-\mathrm{C}_{28} n$-alkanes, computer matching with the WILEY275.L library and as well as by comparison of their mass spectra with those of authentic samples or with data already available in the literature (Adams, 1995; Swigar, Silverstein, 1981). The percentage composition of the identified compounds was computed from the GC peaks areas without any correction factors and was calculated relatively.

\section{Experimental animals}

Male NMRI mice (20-25 g) were used throughout this study. Animals were housed in groups of 6-8 and were allowed free access to food and water except for the short time they were removed from their cages for testing. All experiments were conducted between $10.00 \mathrm{a} . \mathrm{m}$. and 13.00 p.m., with normal room light ( $12 \mathrm{~h}$ regular light/ dark cycle) and temperature $\left(22 \pm 1^{\circ} \mathrm{C}\right)$. All procedures were carried out in line with the institutional guidelines for animal care and use (ethical approval number: 3183 ). Each mouse was used only once.

\section{Analgesic activity}

The hot plate assay method was used for the purpose of preferential assessment of a possible centrally mediated analgesic effect of TBEO (McDonald et al., 1946). Morphine was also used as positive control substance. Six groups of six mice were fasted overnight prior to the start of the experiment, while given free access to water. For 3 consecutive days preceding the experiments, mice (20-25 g) were placed on a plate maintained at room temperature for $15 \mathrm{~min}$ each day. The vehicle (sweet almond oil, $10 \mathrm{mg} / \mathrm{kg}$ ) was given to the first group by intraperitoneal injection. Morphine $(5 \mathrm{mg} / \mathrm{kg})$ and TBEO $(50,100,200$ and $400 \mathrm{mg} / \mathrm{kg})$ were also administered to the second to sixth groups by the same route. Each animal was then placed gently on a $55^{\circ} \mathrm{C}$ hot plate. Latency to exhibit nociceptive responses, such as licking paws or jumping off the hot plate, was determined at 15, 30, 45 and $60 \mathrm{~min}$ after administration of the test substances or vehicle (McDonald et al., 1946).

\section{Anti-inflammatory activity}

Acute anti-inflammatory activity was assessed based on the inhibition of paw edema induced by the injection of $0.1 \mathrm{~mL} 2 \%$ carrageenan into the sub-plantar region of the right hind paw of the rat (Winter, Risley, Nuss, 1962). Male rats were divided into four different groups of 6 
animals each that separately received the vehicle, sweet almond oil (10 mg/kg), Mefenamic acid (30 mg/kg) and TBEO $(100,150$ and $250 \mathrm{mg} / \mathrm{kg})$, intraperitoneally $1 \mathrm{~h}$ before the injection of carrageenan. Paw volume was measured after $0.5,1,2,3$ and $4 \mathrm{~h}$ after the carrageenan administration using a Plethysmometer (model PM 4500, Borj Sanat, Iran).

\section{Statistical analysis}

The data were expressed as mean values \pm S.E.M. and tested using analysis of variance followed by the multiple comparison test of Tukey-Kramer.

\section{RESULTS}

Analgesic activity: Using the hot plate test, it was shown that intraperitoneal administration of 100 $\mathrm{mg} / \mathrm{kg}$ dose of TBEO had significant anti-nociceptive activity in comparison to vehicle group only; the antinociceptive activity of TBEO was less than the standard drug, morphine. TBEO with low and high doses of 50 and
$250 \mathrm{mg} / \mathrm{kg}$ practically did not increase the reaction time in tested animals against the thermal source (Figure 1a). Morphine significantly showed anti-nociceptive activity in hot-plate test. Intraperitoneal co-administration of low doses of morphine $(0.5 \mathrm{mg})$ and effective dose of TBEO $(100 \mathrm{mg})$ in rats was not associated with a significant response in hotplate latency in comparison to TBEO (100 mg) group (Figures 1b).

Vehicle, Morphine ( $5 \mathrm{mg} / \mathrm{kg}$; IP) or TBEO (50, 100,150 and $250 \mathrm{mg} / \mathrm{kg}$, IP) were administered $15 \mathrm{~min}$ prior to the placement of the animal on the hot plate and reaction time of mice was measured at 15-min intervals for one hour.

Opioid independence analgesic action: Naloxone $(5.0 \mathrm{mg} / \mathrm{kg}$, IP) did not significantly change the antinociceptive effect of the TBEO in hot plate test (Figure 2). Whereas; morphine-induced analgesia $(5.0 \mathrm{mg} / \mathrm{kg})$ was completely reversed at the presence of naloxone.

Anti-inflammatory activity: The anti-inflammatory effect of TBEO in rat paw edema induced by carrageenan was established using the essential oil administered intraperitoneally (Figure 3). TBEO with lower doses of

(a) TB essential oil

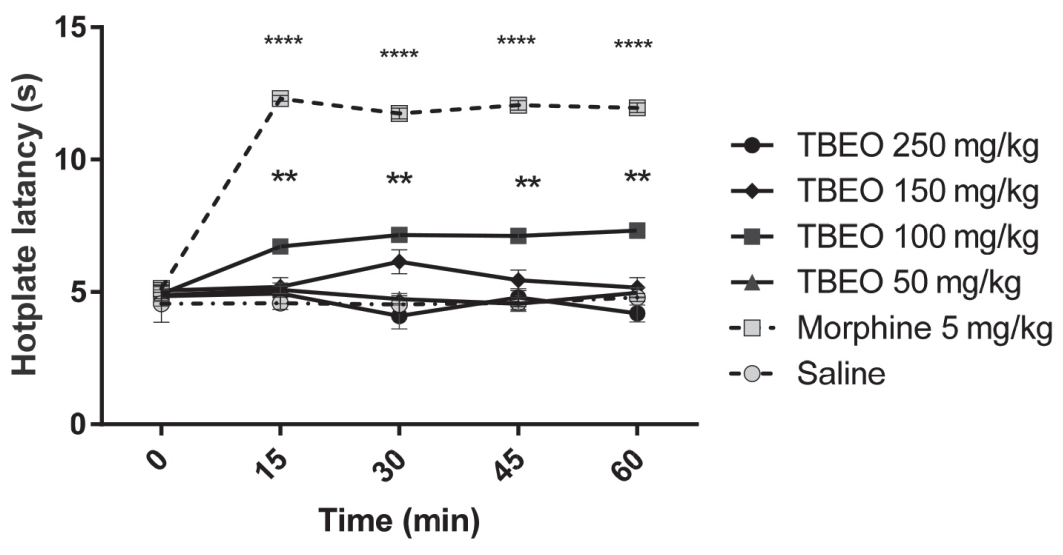

(b) TB essential oil

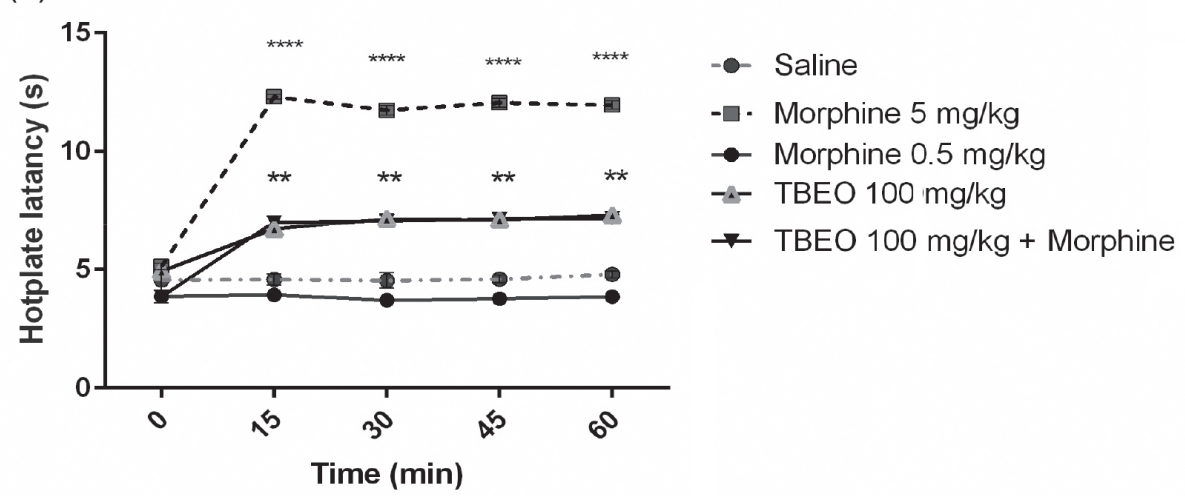

FIGURE 1 - Anti-nociceptive activity of TBEO in the Hot Plate Test. Data represent Mean \pm SEM of six to eight animals in each group $* * \mathrm{P}<0.01$. ${ }^{* * * *} \mathrm{P}<0.0001$, compared with the control group. 


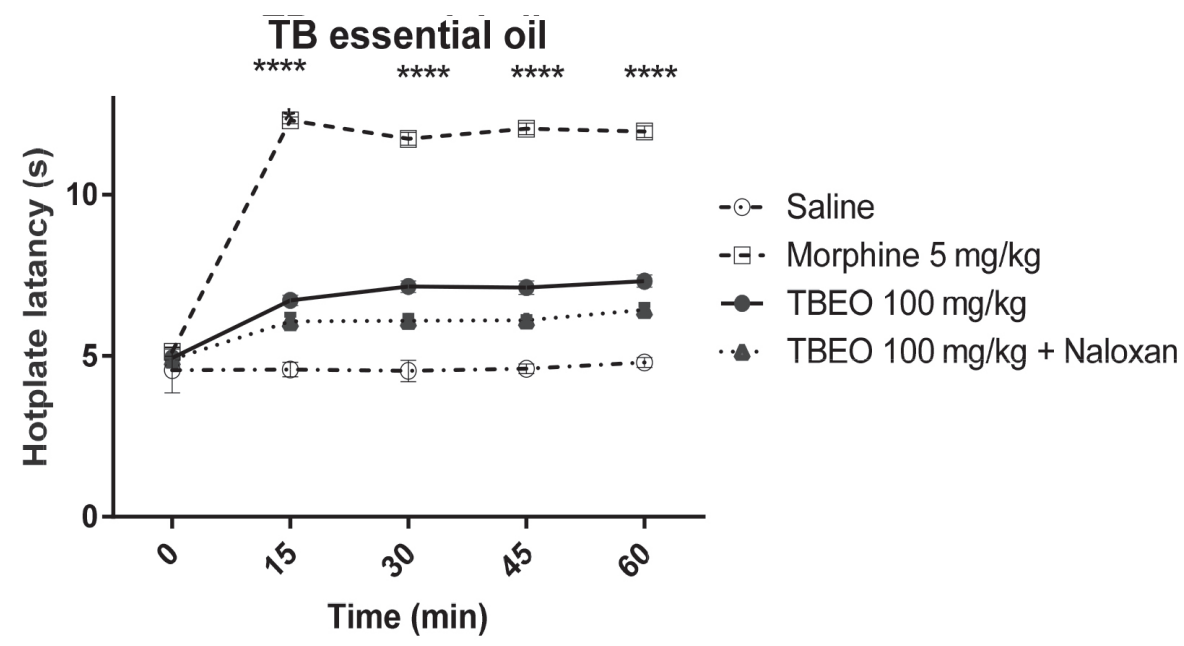

FIGURE 2 - Opioid independence analgesic activity of TBEO. Data represent Mean $\pm \mathrm{SEM}$ of six to eight animals in each group. $* * * * \mathrm{P}<0.0001$ compared with the control group.

After $0.5 \mathrm{~h}$

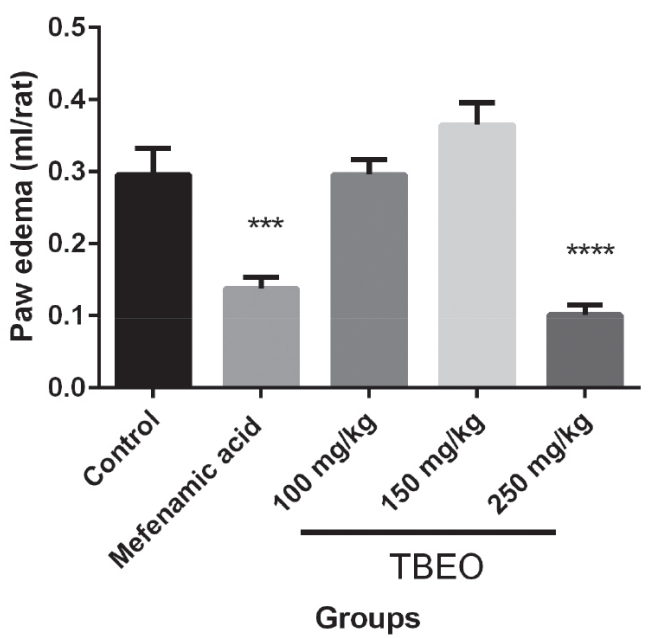

After $3 \mathrm{~h}$

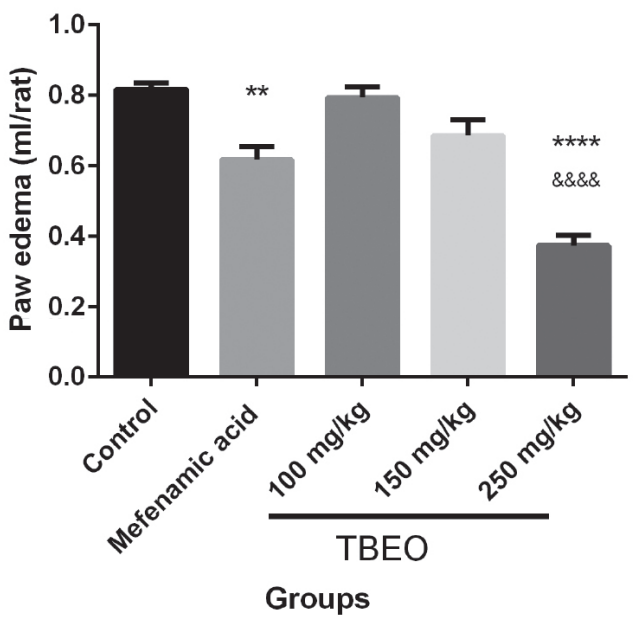

After $1 \mathrm{~h}$



After $4 \mathrm{~h}$

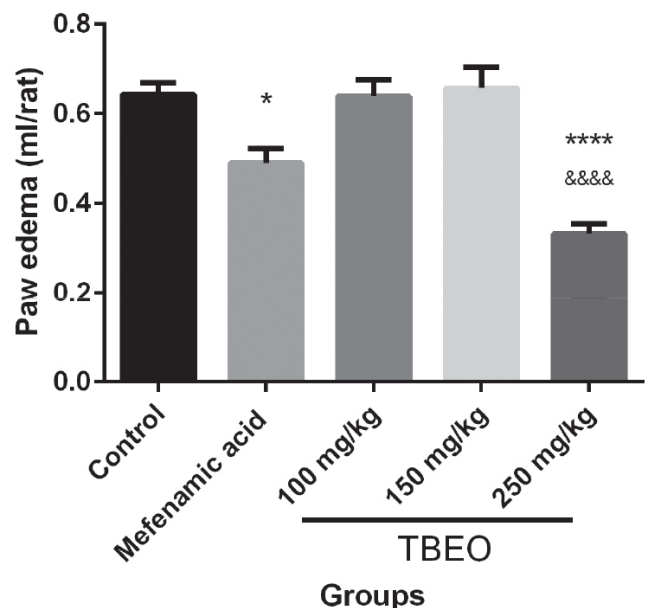

FIGURE 3 - Effects of TBEO on Carrageenan induced inflammation in the $0.5,1,3$ and 4 hour after the injection of carrageenan. Values represent Mean $\pm \operatorname{SEM}(\mathrm{n}=6-8) . * \mathrm{P}<0.05, * * \mathrm{P}<0.01, * * * \mathrm{P}<0.001$ and $* * * * \mathrm{P}<0.0001$ in compared to control, $\& \& \& \& \mathrm{P}<0.0001$ in compared to Mefenamic acid. 
In vivo analgesic and anti-inflammatory effects of the essential oil from Tanacetum balsamita L.

TABLE I - Effect of TBEO on the carrageenan induced inflammation

\begin{tabular}{lcccccc}
\hline Groups & Dose $\mathbf{( m g / k g )}$ & $\mathbf{0 . 5 h}$ & $\mathbf{1 h}$ & $\mathbf{2 h}$ & $\mathbf{3 h}$ & $\mathbf{4 h}$ \\
\hline Mefenamic Acid & $\mathbf{3 0}$ & 53.59 & 46.68 & 40.61 & 24.46 & 23.79 \\
TBEO & $\mathbf{1 0 0}$ & 0.08 & 0.03 & 4.16 & 2.87 & 0.47 \\
TBEO & $\mathbf{1 5 0}$ & 0 & 0 & 12.45 & 16.21 & 0 \\
TBEO & $\mathbf{2 5 0}$ & 65.91 & 57.14 & 59.18 & 54.13 & 48.29 \\
\hline
\end{tabular}

Each value represents the mean \pm SEM (\%inhibition) of 6 rats

100 and $150 \mathrm{mg} / \mathrm{kg}$ practically did not inhibit the paw edema induced by carrageenan in comparison to control. TBEO $(250 \mathrm{mg} / \mathrm{kg})$ as well as Mefenamic acid $(30 \mathrm{mg} / \mathrm{kg})$ significantly inhibited $(\mathrm{p}<0.05)$ the carrageenan-induced rat paw edema formation which was determined at the third hour of the experiment (peak of edema formation) by 54.91 and $24.46 \%$, respectively. At the fourth hour of experiment, this edema inhibition has reached 48.29 and $23.79 \%$.
Anti-inflammatory activity was revealed as the inhibition percent of the edema when compared with the control group (Table I).

TBEO was analyzed by GC/MS to determine the possible compounds responsible for the observed analgesic and anti-inflammatory activities. As shown in Table II, forty four components were identified in this oil which presented about $84.1 \%$ of the total chromatographic material. The

TABLE II - GC-MS analysis of TBEO

\begin{tabular}{|c|c|c|c|c|}
\hline NO. & Compound $^{\mathrm{a}}$ & $\mathbf{K I}^{\mathbf{b}}$ & $\mathbf{K I}^{\mathbf{c}}$ & Content (\%) \\
\hline$\overline{1 .}$ & $\alpha$-Pinene & 938 & 939 & 0.1 \\
\hline 2. & Camphene & 951 & 954 & 0.1 \\
\hline 3. & Verbenene & 970 & 968 & 0.1 \\
\hline 4. & Sabinene & 973 & 975 & 0.3 \\
\hline 5. & $\beta$-Pinene & 979 & 979 & 0.1 \\
\hline 6. & $\alpha$-Terpinene & 1019 & 1017 & 0.1 \\
\hline 7. & $\rho$-Cymene & 1022 & 1025 & 1.0 \\
\hline 8. & Limonene & 1030 & 1029 & 1.5 \\
\hline 9. & $\gamma$-Terpinene & 1057 & 1060 & 0.3 \\
\hline 10. & $\alpha$-Thujone & 1099 & 1102 & 11.9 \\
\hline 11. & $\beta$-Thujone & 1117 & 1114 & 2.2 \\
\hline 12. & $\rho$-Mentha-2,8-diene-1-ol & 1120 & 1123 & 1.2 \\
\hline 13. & trans-Pinicarveol & 1142 & 1139 & 0.2 \\
\hline 14. & Isoborneol & 1153 & 1156 & 0.5 \\
\hline 15. & 4-Terpineol & 1179 & 1177 & 0.6 \\
\hline 16. & trans- $\rho$-Mentha-1(7),8-diene-2-ol & 1181 & 1185 & 0.6 \\
\hline 17. & dihydrocarvone & 1198 & 1193 & 1.1 \\
\hline 18. & trans-Carveol & 1215 & 1217 & 1.5 \\
\hline 19. & Carvone & 1239 & 1242 & 39.8 \\
\hline 20. & Chrysanthenyl acetate & 1167 & 1262 & 0.4 \\
\hline 21. & Carvacrol & 1302 & 1299 & 0.6 \\
\hline 22. & $\alpha$-Cubebene & 1349 & 1351 & 0.1 \\
\hline 23. & Carvyl acetate & 1355 & 1352 & 0.3 \\
\hline 24. & $\alpha$-Copaene & 1380 & 1377 & 0.3 \\
\hline 25. & $\beta$-Damascenone & 1392 & 1391 & 0.1 \\
\hline
\end{tabular}


TABLE II - GC-MS analysis of TBEO (cont.)

\begin{tabular}{|c|c|c|c|c|}
\hline NO. & Compound $^{\mathrm{a}}$ & $\mathbf{K I}^{\mathbf{b}}$ & $\mathbf{K I}^{\mathbf{c}}$ & Content (\%) \\
\hline 26. & cis-Jasmone & 1398 & 1393 & 0.1 \\
\hline 27. & Gurjunene & 1414 & 1410 & 0.1 \\
\hline 28. & $\beta$-Caryophyllene & 1422 & 1418 & 0.4 \\
\hline 29. & $\beta$-Farnesene & 1455 & 1457 & 0.3 \\
\hline 30. & Germacrene D & 1483 & 1485 & 3.0 \\
\hline 31. & $\alpha$-Murrolene & 1503 & 1500 & 0.1 \\
\hline 32. & $\beta$-Bisabolene & 1510 & 1506 & 5.0 \\
\hline 33. & $\delta$-Cadinene & 1529 & 1524 & 2.2 \\
\hline 34. & trans- $\gamma$-Bisabolene & 1539 & 1541 & 1.0 \\
\hline 35. & cis- $\alpha$-Bisabolene & 1555 & 1551 & 0.3 \\
\hline 36. & Nerolidol & 1559 & 1563 & 0.3 \\
\hline 37. & Spathulenol & 1577 & 1578 & 0.6 \\
\hline 38. & Caryophyllene oxide & 1586 & 1583 & 0.2 \\
\hline 39. & Dillapiol & 1619 & 1622 & 0.2 \\
\hline 40. & $\alpha$-Cadinol & 1628 & 1626 & 2.1 \\
\hline 41. & t-Muurolol & 1650 & 1646 & 1.3 \\
\hline 42. & 2,5,10-trimethyl-6,7,8,9- & 1732 & - & 1.2 \\
\hline 43. & tetradehydrocyclopentadecenone-6,10,14-Trimethyl-2-pentadecanone & 1851 & 1846 & 0.2 \\
\hline \multirow[t]{2}{*}{44.} & Phytol & 2119 & 2114 & 0.5 \\
\hline & Total & & & 84.1 \\
\hline
\end{tabular}

${ }^{\mathrm{a}}$ Compounds listed in order of elution. ${ }^{\mathrm{b}} \mathrm{KI}$ (Kovats index) measured relative to $n$-alkanes $\left(\mathrm{C}_{9}-\mathrm{C}_{28}\right)$ on the non-polar DB-5 column under condition listed in the Materials and Methods section. ${ }^{\mathrm{C} I}$, (Kovats index) from literature.

major constituents of the oil were characterized as Carvone (39.8\%) and $\alpha$-Thujone (11.9\%).

\section{DISCUSSION}

The obtained results showed that the TBEO had the most significant anti-inflammatory effect at the dose of $250 \mathrm{mg} / \mathrm{kg}$ among experimental doses $(100,150$ and $250 \mathrm{mg} / \mathrm{kg}$ ).

The essential oil in the dose of $250 \mathrm{mg} / \mathrm{kg}$ had significant anti-inflammatory effects in comparison to the control group. It also had significantly meaningful anti-inflammatory effect at the $3^{\text {rd }}$ and $4^{\text {th }}$ hours after the induction of the inflammation rather than standard drug Mefenamic acid $(30 \mathrm{mg} / \mathrm{kg})$.

In hot plate test, TBEO could meaningfully increase the reaction time against thermal stimulant at the dose of $100 \mathrm{mg} / \mathrm{kg}$. Nevertheless, in comparison to the standard drug (Morphine $5 \mathrm{mg} / \mathrm{kg}$ ), the essential oil was less effective at different times. In order to investigate whether or not the opioid system had a role in antinociceptive effects, some complementary experiments were conducted. We injected $100 \mathrm{mg} / \mathrm{kg}$ of the examined essential oil plus an ineffective dose of Morphine $(0.5 \mathrm{mg} / \mathrm{kg})$ into the mice. The results showed no significant changes in anti-nociceptive effects. This test revealed that the anti-noceptive mechanism of the essential oil at this dose is probably non-opioid. Injecting Naloxane (opioid receptor antagonist) plus essential oil $100 \mathrm{mg} / \mathrm{kg}$ confirmed this suggestion.

Previous study reported that the Tanacetum sp. oil possessed digestive, diuretic, antitussive, analgesic/antiinflammatory and antimicrobial effects (Lotfipour et al., 2008; Yousefzadi et al., 2009). In support of our findings, it has been demonstrated that Tanacetum sp. oil possessed analgesic and anti-inflammatory effects (Lotfipour et al., 2008; Yousefzadi et al., 2009). Some of the medicinal Tanacetum species such as T. microphyllum and T. larvatum were useful for treating various inflammatory disorders and have shown protective activities against indomethacininduced ulcerogenesis, respectively (Petrovic et al., 2003). The analgesic and anti-inflammatory property was also found in extract of other Tanacetum genus such as T. parthenium. 
It was previously mentioned that the monoterpenoid carvone was the main component found in many plant species. Previous studies showed that carvone (Gonçalves et al., 2008) and carvone derivatives, such as rotundifolone (Sousa et al., 2007) and hydroxydihydrocarvone (de Sousa et al., 2006) possessed antinociceptive and analgesic properties. In line with our study, Gonçalves et al. (2008) reported that the analgesic effect of (-)-carvone was not reversed by the opiate antagonist naloxone in the acetic acid-induced writhing test. The anti-nociceptive effects of (-)-carvone represented by inhibition of the licking response of mice in both phases of the formalin test also revealed the involvement of central or peripheral mechanisms in this way (Gonçalves et al., 2008). Moreover, previous studies indicated that Carvone, had intestinal antispasmodic and anti-nociceptive activity (Sousa et al., 2007). In a previous study, the antispasmodic effect of (-)-carvone as a potent calcium channel blocker, in the guinea pig ileum was reported (Souza et al., 2013).

Research on experimental animals confirmed the anti-inflammatory and anti-nociceptive effects of the synthetic compound $\alpha$ and $\beta$ epoxy carvone (da Rocha et al., 2013) and cyane-carvone (Marques et al., 2014). Carvone decreases the formation of inflammatory cytokines and it also has a role in oxidative stress mechanisms. The anti-inflammatory effects of carvone in carrageenan induced edema and the measurement of Myeloperoxidase showed that the most important cytokines having a role in inflammatory mechanisms are IL- $\beta 1$ and TNF $\alpha$ (Marques et al., 2014).

As already assumed, carvone, as the main component of the essential oil, has been reported several times to have anti-inflammatory and anti-nociceptive effects. Thus, the observed anti-inflammatory and antinociceptive effects were probably caused by the high content of carvone in the essential oil. TBEO could be an appropriate choice to develop new anti-nociceptive and anti-inflammatory drugs which had fewer side effects than the typical drugs, though sub-chronic and dermal toxicity tests are strongly recommended to be done on the essential oil.

\section{ACKNOWLEDGMENTS}

Supports from the Faculty of Pharmacy, Tehran Medical Sciences, Islamic Azad University are gratefully acknowledged.

\section{REFERENCES}

Adams RP. Identification of Essential Oil Components by Gas Chromatography/Mass Spectroscopy. Illinois: Allured Publishing Co., Carol Stream; 1995.

da Rocha, ML, Oliveira LE, Patricio Santos CC, de Sousa DP, de Almeida RN, Araujo DA. Anti-nociceptive and antiinflammatory effects of the monoterpene $\alpha, \beta$-epoxy-Carvone in mice. J Nat Med. 2013;67(4):743-9.

de Sousa DP, de Sousa Oliveira F, de Almeida RN. Evaluation of the central activity of hydroxydihydrocarvone. Biol Pharm Bull. 2006;29(4):811-12.

Gonçalves JCR, de Sousa Oliveira F, Benedito RB, de Sousa DP, de Almeida RN, de Araujo DA. Anti-nociceptive activity of (-)-Carvone: evidence of association with decreased peripheral nerve excitability. Biol Pharm Bull. 2008;31(5):1017-20.

Hayes N, Foreman J. The activity of compounds extracted from feverfew on histamine release from rat mast cells. J Pharm Pharmacol. 1987;39(6):466-70.

Johnson ES, Kadam NP, Hylands DM, hylands PJ. Efficacy of feverfew as prophylactic treatment of migraine. Br Med J. 1985;291(6495):569-73.

Lotfipour F, Nazemiyeh H, Fathi-Azad F, garaei N, Arami S, Talat S, Sadegpour F, Hasanpour R. Evaluation of antibacterial activities of some medicinal plants from North-West Iran. Iran J Basic Med Sci. 2008;11(2):80-5.

Marques TH, Marques ML, Medeiros JV, Silva RO, dos Reis Barbosa AL, Lima TC, de Sousa DP, de Freitas RM. Cyane-Carvone, a synthetic derivative of carvone, inhibits inflammatory response by reducing cytokine production and oxidative stress and shows anti-nociceptive effect in mice. Inflammation. 2014;37(3):966-77.

McDonald AD, Woolfe G, Bergel F, Morrison AL, Rinderknecht $\mathrm{H}$. Analgesic action of pethidine derivatives and related compounds. Brit J Pharmacol. 1946;1(1):4-14.

Mozaffarian V. A Dictionary of Iranian Plant Names. Tehran, Farhang Moaser Press; 2006.

Nickavar B, Amin G, Mehregan N. Quercetine, a major flavonol aglycon from Tanacetum balsamita L.. Iran J Pharm Res. 2010;2(4):249-50. 
Petrovic SD, Dobric S, Bokonjic D, Niketic M, GarciaPineres A, Merfort I. Evaluation of Tanacetum larvatum for an anti-inflammatory activity and for the protection against indomethacin-induced ulcerogenesis in rats. J Ethnopharmacol. 2003;87(1):109-13.

de Sousa DP, Junior EV, Oliviera FS, de Almeida RN, Nunes XP, Barbosa-Filho JM. Anti-nociceptive activity of structural analogues of Rotundifolone: structure-activity relationship. Z Naturforsch C. 2007;62(1-2):39-42.

Souza FV, da Rocha MB, de Souza DP, Marcal RM. (-)-Carvone: Antispasmodic effect and mode of action. Fitoterapia. 2013;85:20-24.
Swigar AA, Silverstein RM. Monoterpenes. Milwaukee, WI: Aldrich Chemical Company Publ.; 1981.

Winter CA, Risley EA, Nuss GW. Carrageenin-induced edema in hind paw of the rat as an assay for anti-inflammatory drugs. Exp Biol Med. 1962;111(3):544-7.

Yousefzadi M, Ebrahimi SN, Sonboli A, Miraghasi F, Ghiasi S, Arman M, Mosaffa N. Cytotoxicity, antimicrobial activity and composition of essential oil from Tanacetum balsamita L. subsp. balsamita. Nat Prod Commun. 2009;4(1):119-22.

Received for publication on $03^{\text {rd }}$ May 2018 Accepted for publication on $02^{\text {nd }}$ December 2018 